\title{
MEMAHAMI CARA KERJA PRAGMATISME DALAM PENDIDIKAN: REFLEKSI KRITIS ATAS FILM LASKAR PELANGI
}

\section{Moch Najib Yuliantoro}

Fakultas Filsafat Universitas Gadjah Mada, Indonesia.

Email:mnajib@ugm.ac.id

\section{Abstrak}

Tulisan ini bertujuan untuk memahami cara kerja pemikiran Pragmatisme dalam praktik pendidikan. Sebagai studi kasus, digunakan film Laskar Pelangi karya Riri Reza untuk mengetahui bagaimana praktik pemikiran Pragmatisme dalam pendidikan di Indonesia. Dengan menggunakan metode penulisan deskriptif-kritis dan interpreteasi, diketahui bahwa para tokoh utama dalam film Laskar Pelangi mengalami situasi dilema yang mengarahkan mereka untuk memilih jalan hidup berdasarkan logika internal dan pengalaman aktualnya. Adapun kritik atas, sekaligus implikasi dari, pemikiran pragmatisme adalah potensialitasnya yang terjatuh pada cara berpikir individualistik terutama di ranah aksiologis, yakni dengan mempercayai bahwa tidak ada nilai-nilai universal dalam kehidupan sosial.

Kata Kunci: pragmatisme, pendidikan, Laskar Pelangi

\section{Abstract}

This paper aims to understand the Pragmatism way of thinking in the practice of education. As a case study, Riri Reza's Laskar Pelangi is used to find out how Pragmatism practices in education in Indonesia. By using descriptivecritical method of interpretation and interpretation, it is revealed that the main characters in the film Laskar Pelangi experience a dilemma situation that leads them to choose a way of life based on internal logic and actual experience. As for the criticisms, as well as the implications of, pragmatism thinking refers its potentiality to the individualistic way of thinking, especially in the axiological sphere, namely by believing that there is no universal value in social life.

Keywords: pragmatism, education, Laskar Pelangi

"Setiap pengalaman adalah kekuatan yang menggerakkan" - John Dewey, Experience and Education

\section{PENDAHULUAN}

"Laskar Pelangi" adalah sebuah film historis-edukatif karya sineas muda berbakat, Riri Reza, dan produser ternama, Mira Lesmana. Diangkat dari sebuah novel berjudul sama karya 
"otobiografi" Andrea Hirata (terbit pertama, 2005). Biarpun sedikit berbeda dalam penuturan cerita dari novel aslinya, film ini berkisah tentang perjuangan dan persahabatan sebelas bocah, yang disebut "Laskar Pelangi", beserta dua gurunya di sebuah sekolah sederhana di Pulau Belitong.

Masing-masing tokoh dalam film tersebut digambarkan sering dibenturkan dengan beragam pilihan dilema, untuk memilih dan menyiasati jalan hidup yang lebih bermanfaat bagi mereka. Pilihan $\mathrm{Bu}$ Mus menjadi guru di SD itu, misalnya, adalah sebuah pilihan pragmatis demi mempertahankan cita-cita keluarga besarnya. Pilihan itu, bagi Bu Mus, mesti ambil agar nilai-nilai pendidikan Islam tetap bersinar di tanah Belitong. Setali tiga uang ketika Lintang harus memilih menarik diri dari bangku sekolah selepas ayahnya meninggal. Pilihan itu dengan sadar ia ambil berdasarkan pertimbangan manfaat yang lebih besar ketimbang hanya tetap bersimpuh di bangku sekolah. Empat anggota keluarga (di buku novel bahkan ditulis empat belas!) menggantungkan kebutuhan ekonominya kepada anak sekecil itu lantaran ia adalah putra laki-laki tertua.

Dua benang merah dalam film, yang sejalur dengan pemikiran pragmatisme: (1) usaha untuk meraih kualitas pengalaman, melalui pendidikan, untuk mendapatkan nilai pengalaman lebih besar di masa depan; (2) keharusan menentukan pilihan-pilihan pragmatis, dalam pengertian "mana yang lebih bermanfaat, menurut mereka saat ini atau esok", adalah potret menarik yang patut diulas lebih lanjut.

Istilah "pendidikan" dalam tulisan ini, dengan demikian, tidak dibatasi pengertiannya hanya di bangku sekolah-dalam konteks kelembagaan-saja, namun perlu diperluas, yakni seluruh proses mengetahui dari beragam aspek kehidupan dalam tutur kisah tokohtokoh tersebut. Hal ini cukup beralasan sebab cara mereka berpikir dan menyiasati jalan hidup adalah bentuk akumulasi dari kecerdasan internal subjek, serta hasil interaksi erat dengan situasi lingkungan yang ada, sehingga melahirkan pengalaman-pengalaman yang kaya. Bahkan, proses pendidikan dalam pengertian terakhir tersebut justru 
memiliki pengaruh lebih mendalam daripada pengalaman pendidikan formal biasa.

Bukanlah mengada-ada apabila kemudian penulis mengulas empat pokok pembahasan yang akan menjadi fokus tulisan ini: (1) kerangka teoritis tulisan, yakni konsep "pengalaman" pragmatisme; (2) penjelasan singkat film "Laskar Pelangi"; (3) analisis tentang konsep "pengalaman" pragmatisme dalam film; (4) beberapa catatan refleksi kritis penulis mengenai kelemahan dan kekuatan teori dan film sebelum kemudian menuju catatan penutup.

\section{PENGALAMAN: BASIS PENDIDIKAN PRAGMATISME}

Pragmatisme adalah paham filsafat yang cukup berpengaruh dari Amerika pada Abad 20. Beberapa pemikir yang sering disebut-sebut menekuni paham ini adalah Charles S. Peirce (1839-1914), William James (1842-1910), dan John Dewey (1859-1952). Dalam tulisan ini, penulis akan membatasi pembahasan pada tokoh terakhir, sebab di tangan Dewey, gagasan pragmatisme muncul lebih mengesankan dan merangsang eksperimentasi teori dan praktik secara luas di Amerika dalam seratus tahun terakhir (Ali, 1993: 143; Knight, 2007: 110).

Salah satu kata kunci dalam filsafat John Dewey secara keseluruhan, dan bukan hanya dalam filsafat pendidikannya, adalah "pengalaman" (experience). Hal ini bisa kita telisik dalam tiga karyanya (Experience and Education, Experience and Nature, Art as Experience) yang secara eksplisit menyebut istilah experience sebagai judul utamanya (Sudarminta, 2004: vii).

Realitas pertama-tama, kata Dewey, adalah realitas untuk dialami, bukan untuk diketahui. Dewey mencoba menjernihkan istilah "pengalaman" ini dari dua reduksi ekstrem: penganut empirisme dan rasionalisme. Pandangan pertama, empirisme, menganggap pengalaman bersifat atomistik dan semata-mata cerapan data inderawi yang bersifat eksternal, tanpa melibatkan kutub internal subjek. Sedangkan padangan kedua, rasionalisme, memahami pengalaman sebagai sumber pengetahuan yang tidak 
pasti, mengecoh, dan bentuk primitif pengetahuan (Dewey, 1966: 200).

Dalam bukunya, Experience and Education, Dewey menerangkan pengertian pengalaman sebagai rangkaian "kontinuitas pengalaman" (experiental continuum), yang bersifat vertikal, dalam bingkai "interaksi" dan "situasi", yang bersifat horisontal. Prinsip ini melibatkan setiap usaha untuk memisahkan antara pengalaman yang secara edukatif bermanfaat dan yang tidak bermanfaat (Dewey, 2004: 19).

"Kontinuitas pengalaman" berarti bahwa setiap pengalaman secara sekaligus mengambil sesuatu dari pengalaman sebelumnya dan mengubah, dengan cara tertentu, kualitas pengalaman sesudahnya (Dewey, 2004: 22; Freire [ed.], 2006: 242). Ketika kita, misalnya, sedang mempelajari peta dunia, maka secara sekaligus, membuka akses pengalaman yang lain, pengalaman baru, di luar pengalaman kita saat ini.

Prinsip kontinuitas ini berlaku tidak sama dalam setiap kasus. Terkadang ia memiliki cara tertentu, dan menghasilkan kualitas pengalaman menuruti cara prinsip itu berada. Realitas, bagi kaum pragmatisme seperti Dewey, dipahami sebagai sesuatu yang terusmenerus berubah, dinamis, menuruti perkembangan pengalaman manusia yang kian meluas (Knight, 2007: 112), dan tidak bersifat metafisis (Gutek, 1988: 90). Karena secara epistemologis manusia adalah makhluk yang masing-masing memiliki pengalaman (Knight, 2007: 119), maka tidak ada lagi kebenaran universal. Kebenaran adalah relatif, karena kebenaran hari ini belum tentu dianggap benar hari esok. Yang benar, sejauh menuntun konsekuensi-konsekuensi efektif bila diterapkan ke dalam masalah praktis dan nyata (O'nel, 2002: 418). Konsekuensinya, secara aksiologis, tidak ada prinsip moralitas yang mengikat secara universal. Apa yang dianggap baik secara etis adalah "apa yang berguna dan berfungsi" menurut pengalaman masing-masing (Knight, 2007: 114-6).

Istilah berikutnya, "interaksi", mengacu pada prinsip menafsirkan pengalaman dalam fungsi, daya, serta menetapkan hak- 
hak yang sama dari dua faktor pengalaman-kondisi objektif dan internal subjek-sehingga kedua faktor tersebut saling mensubordinasi (Dewey, 2004: 30-1; Freire [ed.], 2006: 250). Jika keduanya didekatkan, atau berada dalam "interaksi", maka keduanya akan membentuk apa yang Dewey sebut sebagai "situasi", yakni kehidupan individu dalam dunianya, kenyataan konkretnya, atau semacam rangkaian interaksi antara individu dan benda, atau disingkat dalam satu kata: "lingkungan". Jadi, "lingkungan" dimaknai sebagai kondisi yang saling berinteraksi antara kebutuhan, keinginan, tujuan, dan kapasitas pribadi untuk menciptakan pengalaman yang dimiliki (Dewey, 2004: 32-3; Freire [ed.], 2006: 251$2)$.

Manusia hidup dari lahir sampai mati, seperti itu, berkat apa yang telah dilakukan dan diwariskan dari aktivitas manusia sebelumnya (Dewey, 2004: 26-28). Segala sesuatu akan tergantung pada kualitas pengalaman yang dimiliki tersebut. Pengalaman apapun selalu memiliki dua aspek: keserasian dan ketidakserasian (Dewey, 2004: 12). Jika rangkaian pengalaman tersebut berpadu secara utuh (integrated), maka kualitas pengalaman tersebut bisa disebut serasi. Dan bila sebaliknya, terpecah-pecah, tidak terkait, maka kualitas pengalaman itu akan berantakan, tidak serasi. Akibatnya, kata Dewey, bisa berupa kegilaan (Dewey, 2004: 34).

Berdasarkan landasan teoritis tentang "pengalaman" di atas, maka fungsi pendidikan adalah sebagai usaha terus-menerus untuk menyusun kembali (reconstruction) dan menata ulang (reorganization) pengalaman hidup subjek didik supaya mencapai pengalaman yang lebih berkualitas (Sudarminta, 2004: x). Pendidikan adalah bagian dari pengalaman itu sendiri, saat ini, yang jelas-jelas ada, bukan masa depan yang masih abstrak dan-seringkali tanpa tersadariterkendalikan oleh khayalan (Dewey, 2004: 39).

Suatu pendidikan hendaknya menciptakan pengalaman yang merangsang keingintahuan, memperkuat inisiatif, dan melahirkan tujuan yang intens bagi anak didik (Dewey, 2004: 25). Adalah tugas pendidik untuk menemukan ke mana arah tujuan pengalaman itu 
berjalan. Pendidik perlu menilai sikap apa yang betul-betul kondusif bagi kesinambungan pertumbuhan dan sikap apa yang menciderainya. Pendidik perlu pula melahirkan sikap empatik terhadap apa yang benar-benar sedang dipikirkan oleh anak didik yang sedang belajar. Ia tidak hanya menyadarkan prinsip umum mengenai pengalaman aktual dari kondisi lingkungan, serta keadaan fisik dan sosial yang ada, tetapi menarik keadaan itu untuk membangun pengalaman yang berfaedah (Dewey, 2004: 26-8).

Dengan demikian, prinsip kontinuitas dalam aplikasi pendidikan mengandung arti bahwa masa depan harus diperhitungkan pada tingkat proses pendidikan saat ini (Dewey, 2004: 36). Sikap demokratis, menghargai kebebasan individu, kebaikan hati dan kesopanan, adalah beberapa prinsip penting yang kelak dapat meningkatkan kualitas pengalaman (Dewey, 2004: 21). Dewey menerangkan bahwa konsep pengalaman tidak hanya berpatok pada hal-hal yang bersifat eksternal, namun juga menghargai intenal subjek, yakni intelektual dan moral. Oleh karena sikap-sikap ini adalah apa yang berlaku di masa depan, maka sikap penting yang harus dibentuk adalah sikap ingin terus belajar dan kemampuan belajar dari pengalaman yang kita miliki saat ini (Dewey, 2004: 38-39).

\section{FILM "LASKAR PELANGI": SKETSA OBJEK MATERIAL}

"Laskar Pelangi" adalah nama sebuah film garapan sineas muda Riri Reza yang diproduksi oleh Miles Film pimpinan Mira Lesmana. Pertama launching, tanggal 25 September 2008. Film ini diangkat dari novel best seller, dengan judul yang sama, buku pertama dari tetralogi "Laskar Pelangi" karya Andrea Hirata. Baik keempat buku maupun filmnya, telah mendapat sambutan positif dari berbagai kalangan, mulai anak-anak hingga kakek-nenek, mulai tukang cukur sampai presiden beserta istri, dari dalam dan luar negeri. Sebuah prestasi mengejutkan untuk karya pertama dan pemula di bidang sastra. Berikut penulis paparkan sekilas kisah film tersebut.

Alkisah, terdapat sebuah sekolah renta di Pulau Belitong bernama SD Muhammadiyah. Diasuh oleh tiga orang guru: Muslimah Hafsari 
(Bu Mus), Harfan Effendy Noor (Pak Harfan), dan Pak Bakrie (di novel, nama ini tidak ditemukan). Semenjak belia, kira-kira usia lima belas tahun, Bu Mus sudah mengabdikan dirinya di SD ini, meneruskan cita-cita Ayahnya, K.A. Abdul Hamid - salah satu tokoh pelopor SD Muhammadiyah. Begitu pula Pak Harfan, kerabat dekat Ayah Bu Mus, juga tanpa lelah menekuni sekolah ini hingga usia senja dan lepas nyawanya (di novel, Pak Harfan tidak sampai meninggal dunia, bahkan masih hidup hingga murid-muridnya dewasa, kirakira 15 tahun kemudian (Hirata, 2007: 490, 492)).

SD Muhammadiyah hanya memiliki sepuluh murid-Lintang, Ikal, Mahar, Kucai, Samson, Syahdan, Trapani, Sahara, A Kiong, dan Harun-kemudian memperoleh tambahan satu murid baru, Flo, yang berkeras hati pindah dari sekolah berkelas: SD PN Timah, selepas menonton pertunjukkan megah SD Muhammadiyah dalam "Festival 17 Agustus" garapan sutradara cilik: Mahar. Sebelas bocah itu, oleh $\mathrm{Bu}$ Mus, kemudian disebut "Laskar Pelangi"-simbol untuk mengobarkan semangat perjuangan mereka dalam merengkuh ilmu.

Ada tiga faktor mengapa para orangtua menyekolahkan anaknya di sini. Pertama, karena SD Muhammadiyah tidak menetapkan iuran dalam bentuk apapun, para orangtua hanya menyumbang sukarela semampu mereka. Kedua, karena firasat, anak-anak mereka dianggap memiliki karakter yang mudah disesatkan iblis, sehingga sejak usia muda harus mendapat pendadaran Islam yang tangguh, dan SD Muhammadiyah lah satu-satunya sekolah formal yang masih tetap mempertahankan semangat Islam itu. Ketiga, karena memang anaknya tidak diterima di sekolah manapun (Hirata, 2007: 4).

Keadaan gedung SD Muhammadiyah yang buruk dan apa adanya memang tidak bisa lagi disebut sebagai sekolah ideal. Tidak ada seragam, kurikulum, dan miskin fasilitas. Tentu kita masih ingat potongan-potongan film Laskar Pelangi, yang menggambarkan dengan baik latar memilukan sekolah itu, seperti sepatu karet, jeruji kayu sebagai alat hitung, parkir kambing, atap bocor, dinding kayu yang hampir roboh, kapur hutangan dan kadang perlu dijemur dulu 
sebelum dipakai, serta peta Indonesia yang robek yang dikenang cukup menunjukkan "kepandaian" Harun.

SD Muhammadiyah tetap berdiri tegak berkat satu kata: komitmen. Komitmen memperjuangkan prinsip-prinsip agama dan, yang terpenting, mengubah masa depan anak-anak kuli itu keluar dari produk jahiliyah. Pak Harfan tak jarang menerima nasihat orang supaya sekolah itu ditutup saja. Namun dengan tegas dan penuh integritas, Pak Harfan menjawab, "sekolah ini tidak mengejar nilainilai, yang sekedar melengkapi kurikulum, tetapi sekolah ini mengajarkan nilai-nilai luhur, mengajari anak didiknya dari hati".

Begitu banyak peristiwa ganjil, sekaligus menakjubkan, yang terjadi pada masa kecil sebelas Laskar Pelangi dan dua guru terbaiknya. Lintang, salah satu murid pesisir tercerdas di sekolah ini, rela menempuh 80 kilometer, pulang-pergi, untuk memuaskan dahaga ilmunya, bahkan terkadang hanya untuk menyanyikan lagu "Padamu Negeri" di akhir pelajaran. Begitu pula, dengan tokoh-tokoh yang lain. Keadaan sosial dan ekonomi yang tidak bersimpati, diimbuhi biusan provokatif Bu Mus dan Pak Harfan, telah sedemikian kuat mengobarkan semangat juang yang besar di dada mereka: kita harus punya cita-cita, kita harus berubah, kita harus keluar dari jaman jahiliyah ini.

Pak Harfan dan Bu Mus adalah pribadi-pribadi luhur yang mengajarkan keteguhan pendirian, ketekunan, dan keinginan yang kuat dalam mencapai cita-cita. Mereka menyampaikan sebuah prinsip yang diam-diam menyelinap jauh ke dalam sanubari sebelas bocah Laskar Pelangi itu, serta memberi arah hingga mereka dewasa, yaitu: "hiduplah untuk memberi sebanyak-banyaknya, bukan untuk menerima sebanyak-banyaknya".

Di akhir kisah, yakni pada tahun 1991, SD Muhammadiyah terpaksa ditutup, dan Bu Muslimah diangkat sebagai guru PNS, mengajar di SD Negeri 6 Belitong (Hirata, 2007: 486, 488). Sementara itu, dua belas tahun berikutnya, sebelas bocah Laskar Pelangi telah berhasil mencapai cita-citanya masing-masing, kecuali Lintang, Trapani, dan Harun (bagian ini tidak dijelaskan dalam film). 
Ikal berhasil sekolah di Sorbonne, Paris, Perancis. Mahar menjadi budayawan, narasumber tentang budaya, dan menerbitkan bukubuku budaya. Flo-patner terbaik Mahar-juga sudah mulai meninggalkan kehidupan mistik, selalu memakai jilbab, lulus dari Fakultas Keguruan dan Ilmu Pendidikan Universitas Sriwijaya, menjadi guru TK di Tanjong Pandan, serta aktif membangun gerakan wanita Muhammadiyah. Kucai berhasil menjadi politisi, anggota DPRD Belitong, dan memperoleh gelar MBA. Syahdan, yang awalnya bercita-cita menjadi aktor, kini terperosok menjadi network designer handal, lulusan Kyoto University, Jepang (Hirata, 2007: 474, 477, 479, 490).

Trapani mengalami gangguan jiwa karena terjangkit personality disorder dan mother complex. A Kiong, tokoh mediator cinta Ikal dan A Ling, kini menjadi muslim, dan menikahi "kupu-kupu batin"-nya: Sahara. Sekarang mereka sudah punya lima anak, membuka toko kelontong "Sinar Perkasa", dan meminta tokoh macho Laskar Pelangi: Samson, untuk membantunya sebagai staf toko (Hirata, 2007: 453, 466).

Sementara itu, Lintang, murid tercerdas di SD Muhammadiyah, menjadi sopir truk tronton dan, sebagaimana dituturkan dalam buku terakhir dari Tetralogi Andrea, Maryamah Karpov, ia menjadi juragan kopra yang sukses (Hirata, 2008: 267). Walaupun semenjak kecil di hati kecil Lintang berharap menjadi ilmuwan matematika dan sekolah di Sorbonne - asal tahu saja, inspirator utama Ikal sehingga ia berani bercita-cita sekolah di Sorbonne adalah Lintang-, tetapi ia tetap bangga dengan kehidupannya saat ini karena setidaknya ia telah berhasil memenuhi permintaan ayahnya untuk tidak menjadi nelayan (Hirata, 2007: 472). Terakhir, Harun, tetap lucu seperti itu: kalau dulu ia adalah anak kecil yang terperangkap oleh badan orang dewasa, kini ia adalah orang dewasa yang terperangkap dalam alam pikiran anak kecil. Setiap akhir pekan, ia selalu dikunjungi sahabat-sahabat SD-nya secara bergiliran (Hirata, 2007: 466). 


\section{ANALISIS TEORITIS FILM "LASKAR PELANGI"}

Ada setidaknya dua prinsip pragmatisme yang bisa kita temukan cara kerja dan praktiknya dalam film tersebut: (1) usaha meraih kualitas pengalaman melalui pendidikan dan (2) keharusan mengambil keputusan pragmatis dari beberapa pilihan dilematis.

Lintang, misalnya, adalah tokoh yang lahir dari keturunan keluarga nelayan, miskin, dan jauh dari gegap gempita hidup berkecukupan. Tetapi ayahnya yang tidak pernah sekolah itu bersungguh-sungguh menyekolahkan Lintang di SD Muhammadiyah, biarpun jarak tempuhnya mencapai 80 kilometer. Tujuannya hanya satu, berharap dari seorang Lintang, keluarganya bisa keluar dari kebodohan yang sejak lama bersekutu dengan kemiskinan. Ayah Lintang menginginkan agar anaknya bisa merasakan sebuah lingkungan yang lebih berkualitas dari sekedar menjadi nelayan.

Lintang bisa segera mengambil rujukan rasional atas sinyal kuat Ayahnya. Ia padukan dirinya, melalui "interaksi" serasi antara kondisi objektif berupa "situasi" dunia konkretnya, yakni internal subjeknya yang intelek dan bermoral, dengan kegigihan belajar yang susah dibendung kontinuitasnya. Otak cerdas Lintang, dalam perspektif pragmatisme, tidak akan pernah menemukan kecermelangannya jika ia tidak mendapat rangsangan pengalaman dari luar dirinya. Bahu-membahu, seluruh komponen lingkungan Lintang (sekolah, keluarga, sahabat, sepeda, dan buaya yang mau menyingkir) menghantarkannya, membukakan pintu "berani bercitacita tinggi" yang hanya bisa mungkin lahir jika ditangkap secara interaktif oleh internal subjek Lintang. Hasilnya, Lintang benar-benar melakukannya. Ia merasa perlu mempunyai cita-cita tinggi, membaca banyak buku, dan rela menjadi "guru sementara" menggantikan Bu Mus, karena ia tahu bahwa ia sudah menemukan apa yang lebih bermanfaat baginya dari sekedar apa yang ia miliki saat itu. Segala potensi yang ia miliki secara apa adanya dan sungguh-sungguh, ia kerahkan untuk meraih cita-cita itu. "Kita harus punya cita-cita yang 
tinggi, Kal. Di sekolah ini perjalanan itu kita mulai!", semangat Lintang saat memotivasi Ikal.

Tetapi kemudian kontinuitas pengalaman itu menjadi berantakan ketika ayahnya tiada. Situasi dunia konkretnya sudah berbeda dengan situasi sebelumnya. Pengalaman yang sudah jalin-menjalin dan terkait kuat itu luruh, tidak serasi lagi, ketika ia harus menghadapi situasi sulit antara pilihan melanjutkan sekolah atau menggantikan peran ayahnya, mencari nafkah keluarga. Lintang dihadapkan pada pilihan pragmatis. Interaksi yang dilakukan sebelumnya tidak sealur dengan apa yang diharapkan oleh subjek internalnya. Lintang pun kembali harus melakukan interaksi lagi untuk menyambut situasi yang ada. Ia harus memilih. Tetapi kemudian, pragmatisme mengatakan, apapun pilihan Lintang maka ia sudah mempertimbangkan bahwa pilihan itu memiliki konsekuensi-konsekuensi efektif. Yang efektif, menurut pragmatisme, adalah yang dianggap bermanfaat. Dan pilihan Lintang adalah berhenti sekolah, lalu bekerja menghidupi keluarganya. Itulah yang lebih bermanfaat. Saat itu.

Dari sini pemakluman itu kembali terjadi, bahwa idealitas lagilagi dikalahkan oleh pragmatisme hidup. Pendapat terkalahkan oleh pendapatan; logika dikalahkan logistik, begitulah kira-kira bahasa sederhananya. Akhir keputusan Lintang telah menjustifikasi kebenaran pernyataan itu. Sehingga pragmatisme menjadi nyata, karena sesuatu yang bermanfaat itu seringkali berada di dekat kita, dalam diri kita, bukan di luar kita. Muncullah kemudian dalam kondisi tertentu, sikap individualistik - suatu sikap yang akan segera penulis kritik pada pembahasan berikutnya.

Benturan interaksi, akibat situasi yang tidak simpatik itu dialami pula oleh tokoh-tokoh lain. Untuk menyebut sebagian contoh: Pak Bakrie mesti memilih keluar dari SD demi tawaran gaji yang lebih besar dari SD lain, Pak Harfan memanggang kapur-kapur basah di bawah terik matahari dan menyangga dinding kayu sekolahnya dengan kayu lagi, dan Mahar dan kawan-kawannya pergi menemui dukun Tuk Bayan Tula agar ujiannya lulus. Semua itu adalah bentuk- 
bentuk pengalaman yang bernilai pragmatis. Hasil interaksi kondisi objektif dan internal subjek menyatakan bahwa bentuk tindakan itu dianggap bernilai manfaat.

Demikianlah, pengalaman selalu memiliki dua akibat: mendewasakan dan mengerdilkan. John Dewey memaknai dua aspek ini sebagai pengalaman yang mendidik, serasi, bermanfaat, dan pengalaman yang tidak mendidik, tidak serasi, tidak bermanfaat. Dua pengalaman ini kelak yang akan menentukan seberapa besar pengalaman yang akan dipetik dari segi kualitasnya di masa mendatang. Kita saksikan dalam film itu, betapa banyak sekali pengalaman yang amat mendidik, sekaligus mendewasakan, sebagaimana dalam pengertian Dewey.

$\mathrm{Bu}$ Muslimah ternyata cukup peka melihat bakat terpendam masing-masing muridnya. Sebagaimana dibenarkan oleh pragmatisme sekaligus menentang nativisme, bakat tersebut tidak bisa mengalami pertumbuhan sendiri. Ia perlu rangsangan dari lingkungannya. Bu Muslimah bertidak sebagai fasilitator bagi tumbuh kembangnya bakat seni Mahar dengan memilihnya sebagai sutradara "Festival 17 Agustus". Mahar pun tidak menyia-yiakan kesempatan. "Serahkan padaku dan alam...", kelakarnya optimis. Ia yakin memiliki banyak pengalaman dari buku-buku dan cerita yang ia dapatkan sebelumnya. Sehingga ia, dibantu juga oleh Bu Mus, tinggal menyusun kembali (reconstruction) dan menata ulang (recognization) pengalaman-pengalaman yang sudah ada untuk mencapai pengalaman lebih berkualitas saat pertunjukan nanti.

Hal itu terulang kembali ketika Bu Mus memilih tiga delegasi peserta lomba cerdas cermat, mengajarkan nama-nama tumbuhan di luar sekolah, hingga membuatkan "rapor khusus" untuk Harun. Usaha Bu Mus itu merupakan praktik dari sikap empatik seorang pendidik atas apa yang ia anggap kondusif bagi peningkatan kualitas pengalaman anak didiknya. Termasuk kecurigaan Bu Mus terhadap Flo ketika ia begitu dekat dengan murid-murid yang lain, sehingga hampir saja membubarkan kontinuitas pengalaman yang sudah sekian lama dibangun, juga termasuk bagian dari kepekaan seorang 
pendidik terhadap kualitas pengalaman yang "mungkin" akan diperoleh anak didiknya kelak.

Itulah serangkaian pengalaman yang mendewasakan dan mendidik itu. Ketika seorang guru bersedia sepenuh hati menuntun kecenderungan positif yang sudah dimiliki anak didiknya, maka secara otomatis anak didik akan semakin termotivasi meningkatkan kualitas dirinya untuk meraih gambaran-gambaran pengalaman yang secara intens hendak dituju. Lihatlah, bagaimana semangat belajar tiga delegasi kompetisi cerdas cermat itu berkobar-kobar, lantaran sikap empati tulus Bu Mus melatih mereka dan membuatkan baju baru bagi mereka?

Sebagai pendidik, Bu Mus sangat memperhatikan betul apa yang terpikirkan di benak murid-muridnya. Tragedi Harun pandai menggambar seekor kucing saat ujian di SD PN Timah, misalnya, bagi kaum pragmatisme, tetap dianggap wajar karena itu merupakan salah satu hasil dari rekonstruksi pengalaman yang ia peroleh sebelumnya. Eksistensinya sama sekali tidak bisa disamakan dengan murid-murid yang lain. Karena daya internal subjek Harun tidak cukup berhasil menangkap dengan kuat kondisi objektif dan situasi lingkungannya. Ia mengalami proses interaksi yang berbeda-untuk tidak menyebut, tersendat-dari manusia pada umumnya. Sehingga Bu Mus yang perhatian dan peka atas situasi itu, dengan kerelaan hati membuatkan rapor khusus bagi Harun, agar interaksi pengalaman Harun berjalan kontinu sesuai kadar daya tangkap internal subjeknya. Secara etis, Bu Mus tentu menganggap perilaku Harun adalah baik. Ini berarti, bagi kaum pragmatisme, tidak ada sebutan murid bodoh, tetapi yang ada adalah murid yang memiliki kemampuan berbeda. Dan guru sebagai fasilitator, harus memahami dan memfasilitasi ragam perbedaan itu sebaik-baiknya.

Jadi, dalam pragmatisme, kualitas pengalaman memang harus ditangkap dan diarahkan oleh pendidikan. Sedangkan yang akan membentuknya secara untuh adalah anak didik itu sendiri. Dalam film tersebut, proses itu dilakukan melalui, misalnya, penanaman nilai-nilai dasar dalam cerita perahu Nabi Nuh AS oleh Pak Harfan, 
juga nasehat $\mathrm{Bu}$ Mus kepada Kucai agar tidak malu menjadi pemimpin ketika menghadapi anak-anak kuli yang berkelakuan seperti setan itu.

Coba kita renungkan kembali, mengapa Sahara-gadis sepolos itu - sedemikian berani mengharamkan rencana Mahar menemui Tuk Bayan Tula? Itu karena ia sudah memperoleh pengalaman nilai yang mengonstruksi menjadi sebuah keyakinan, bahwa berhubungan dengan dukun adalah syirik dan dosa besar. Begitu pula kejeniusan Mahar men-re-charge baterai kolektifnya di bawah terik matahari, atau mengatakan bahwa "musik Jazz adalah musiknya orang pintar", lagilagi itu hasil dari rekonstruksi pengalamannya. Bahkan, desiran rindu seorang Ikal kepada gadis China Ho Pho, A Ling, yang seringkali ia ungkapkan secara romantis kepada Lintang, "tidak ada wanita di dunia ini secantik A Ling, Boi...", boleh jadi disebabkan oleh pengalaman Ikal yang hanya menemukan wanita yang tidak cantik (?). Akibatnya, ketika bertemu A Ling, ia terasa dibukakan sebuah pengalaman baru, pengetahuan baru, aüfklarung, bahwa istilah bidadari yang sering ia dengar dari guru ngajinya selama ini telah bermetamorfosis ke dalam sosok A Ling. Disinilah letak urgensinya Dewey mengatakan bahwa "setiap pengalaman adalah kekuatan yang menggerakkan". Sekali ia tertancap dalam alam bawah sadar manusia, maka usaha untuk menghapuskannya sampai kapanpun hanya akan berujung pada kesia-siaan belaka.

\section{SIMPULAN}

Di akhir paragraf kelima dari sub pembahasan sebelumnya, penulis mengatakan akan mengulas lebih jauh tentang implikasi dari pragmatisme, yakni sikap individualistik-meskipun, implikasi menuju sikap ini perlu diakui baru bersifat mungkin. Sikap ini muncul bila instrumen sosial, yakni demokrasi, tidak dimanfaatkan oleh penganut pragmatisme sebagai suatu interaksi. Sebuah peluang terbukanya ruang publik bagi medium memenuhi kebutuhan privat.

Konsep pragmatisme John Dewey, sejauh penelusuran penulis, cenderung mengukur kebenaran sebagai apa yang efektif, 
bermanfaat, dan berguna. Realitas bersifat dinamis, berubah-ubah, anti-metafisis. Pragmatisme bahkan mengimani tidak adanya nilai universal yang mengikat manusia. Segalanya serba relatif, dalam pengertian tergantung rekonstruksi pengalaman masing-masing individu.

Secara ontologis dan bahkan epistemologis, pandangan pragmatisme tidak ada problem serius. Sebab, pada kenyataannya realitas memang tidak pernah diam, selalu berubah, tergantung pada situasi lingkungan dan interaksi antara benda dan manusia. Begitu pula, pengalaman amat dominan dalam proses pembentukan pengetahuan manusia. Begitu banyak praktik kehidupan yang menjustifikasi pendapat ini. Namun demikian, kritik yang perlu segera dilayangkan adalah konsekuensi dari dua pandangan tersebut pada wilayah aksiologis, bahwa tidak ada nilai-nilai universal.

Pendapat aksiologi pragmatisme itu akan menemui kesulitan ketika, misalnya, melihat fakta bahwa bangsa-bangsa dapat saling bersatu lantaran meyakini adanya satu nilai yang sama yang bisa mempertemukan mereka. Nilai keadilan, misalnya. Persoalan apa yang dianggap adil oleh setiap individu, bagaimana derivasinya, itu persoalan lain, karena hal itu terkait dengan cara pandang yang digunakan masing-masing. Tetapi bahwa secara prinsip setiap orang percaya adanya nilai keadilan, dalam dirinya sendiri (justice-itself), adalah fakta nilai universal yang sulit untuk ditolak. Bahkan, dalam rentang sejarahnya, manusia sering memikirkan nilai-nilai tersebut, baik dengan menggunakan dasar pemikiran moral, agama maupun rasionalitas modern. Tak berlebihan bila dikatakan bahwa puncak dari segala nilai jika terciptanya suatu keadilan.

Yang adil, bukan berarti yang benar. Dan yang benar, belum tentu adil. Keduanya memiliki implikasi yang berbeda. Keadilan akan berimplikasi pada sikap afirmatif, minus tendensi, dapat dirasakan bersama tanpa membedakan status dan kedudukan. Sedangkan kebenaran bisa berimplikasi pada justifikasi kekerasan, rentan terhadap tendensi, dan mengenal status. Yang adil adalah yang proporsional. Karena itu, nilai keadilan bisa kita sebut sebagai nilai 
universal sebab ia mampu menyetuh proses interaksi setiap individu, bagi/dalam dirinya, dan terhadap lingkungannya: orang lain dan benda-benda. Ia bisa bersifat privat dan sekaligus publik.

Akibat yang dimunculkan dari tiadanya nilai universal pragmatisme adalah pembenaran terhadap sikap individu. Bahwa secara etis olehnya dianggap baik karena lahir dari keputusan sadarnya, belum tentu secara publik hal itu disebut baik, sebab sejatinya, konsekuensi dari sikap individualis adalah mengedepankan kepentingan dalam dirinya sendiri. Keputusan Pak Bakrie keluar dari SD Muhammadiyah, misalnya, adalah analogi yang tepat dari pernyataan ini. Baik secara individual, namun tidak baik secara publik-sosial.

Dengan menarik simpulan aksiologis semacam itu, pragmatisme memang terlihat cukup konsisten dengan pandangan epistemologi dan ontologinya, tetapi di aras berbeda, ia tengah terjerembab ke dalam pandangannya sendiri mengenai instrumen sosial yang menurutnya paling efektif, yakni masyarakat terbuka dan demokratis (open and democratic environment). Bagaimana mungkin padangan sosial itu akan terwujud jika masih membenarkan prinsip kedirian, berupa tolok ukur diri sebagai "eksekutor akhir" dari interaksi pengalaman sosialnya? Jika harus demikian, benar memang, dampaknya tidak ada nilai universal. Tetapi, pada kenyataanya, masyarakat terbuka dan demokratis hanya mungkin terwujud jika terdapat kesepahaman kolektif. Dan kesepahaman kolektif hanya bisa lahir jika dilandasi oleh adanya nilai-nilai universal yang diyakini publik. Nilai keadilan, umpamanya.

Jadi, pragmatisme berada dalam tingkat konsistensi yang elegan jika pandangan epistemologi, ontologi, dan aksiologinya berlaku dalam situasi privat. Namun, akan terlihat gelagapan dari sudut aksiologis, jika berlaku dalam situasi publik. Ketika pragmatisme bicara soal masyarakat terbuka dan demokratis, maka ia sudah memasuki wilayah publik, dan pandangan aksiologinya itu: tiadanya nilai-nilai universal, dengan sendirinya akan runtuh. 
Dengan demikian, jika pragmatisme konsisten dengan pandangan demokrasi terbukanya, dan mengeyampingkan pandangan aksiologinya, maka kasus Lintang putus sekolah itu tidak akan mungkin terjadi. Karena publik akan secara sadar mengedepankan nilai-nilai universal, seperti keadilan mendapatkan hak pendidikan, sebagai basis bertindak dari hasil proses interaksi internal subjek dengan kondisi objektif lingkungannya. Disinilah penulis hendak menyatakan bahwa nilai universal memang ada dan dalam konteks pragamatisme harus difungsikan sebagai pijakan open democratic-semacam, kesadaran kolektif-untuk mereduksi, bahkan menghalau, sikap "anarkisme" individualis, seperti dalam contoh Pak Bakrie.

Selain kritik terhadap konsep teoritis pragmatisme, penulis ingin menyoroti pula tentang beberapa keganjilan dalam film dan novelnya. Pertama, terkait konsistensi film dengan novel. Diantaranya, munculnya tokoh-tokoh fiktif yang sebetulnya tidak ada dalam novel, seperti Pak Bakrie, Pak Mahmud, dan tokoh-tokoh yang dipilih sebagai delegasi kompetisi cerdas cermat. Untuk hal yang terakhir ini, dalam buku novel, delegasi itu adalah Lintang, Ikal, Sahara, dan bukan Mahar. Hal ini boleh jadi sekedar mencari "sensasi" penonton, karena sejak awal, Mahar dikesankan sebagai bocah yang lucu, kocak, dan pandai di bidang seni, sehingga pemilihan Mahar dalam kompetisi itu dianggap tepat. Kedua, munculnya beberapa cerita dan peristiwa fiktif, seperti kematian Pak Harfan; empat keluarga Lintang, (di novel, empat belas); dandanan rapi ayah Ikal-logikanya, ia adalah buruh timah yang kotor, bagaimana mungkin di film bisa serapi itu laksana seorang mandor sukses?; Lintang putus sekolah ketika SMP, bukan SD; dan hidung mancung Lintang dewasatengoklah, bagaimana bentuk hidung Lintang kecil.

Ketiga, adanya usaha menyederhanakan gambaran cerita di novel, seperti terlihat dalam bobot soal yang dilombakan saat kompetisi cerdas cermat. Dalam novel, soal yang diberikan lebih serius, bahkan menyebut istilah-istilah ilmiah setingkat S1/S2. Sementara, di film, soal itu disederhanakan, lebih ringan. Kendati pun, hal ini bisa kita 
anggap wajar, karena namanya adaptasi novel ke film-dan barangkali dirembesi pula oleh peluang bisnis-tentu selalu mempertimbangkan banyak variabel, diantaranya kadar pengetahuan penonton.

Penggunaan istilah-istilah ilmiah dalam novel tak jarang mendapat kritik dari kalangan sastra, terutama terkait logika sastra yang digunakan. Bayangkan bagaimana mungkin anak seusia itu dengan keadaan sosio-kultur, ekonomi, dan pendidikan semacam itu, bisa menggunakan istilah-istilah yang hanya bisa diucapkan oleh orang yang pernah mengenyam pendidikan di perguruan tinggi? Disinilah, letak kritik itu. Andrea seringkali menggunakan istilah hiperbolis berlebihan sehingga terkadang malah merusak logika cerita sastra itu sendiri.

Meskipun terdapat keganjilan di sana-sini, penulis ingin menempatkan diri sebagi murid Rowlands yang baik, bahwa kandungan konseptual dan gagasan jauh lebih penting dari pada kecakapan sastrawi, yang kita tahu seringkali bersifat simbolik (Rowlands, 2004: xxxvi). Setiap ada kelemahan, tentu ada pula kekuatan-dalam beberapa kisah, sumber kekuatan adalah sumber kelemahan itu sendiri. Tetapi, dalam film ini, penulis ingin mengungkapkan satu kekuatan yang melekat di setiap benak penonton seusai menontonnya, yaitu kocak. Ya, film ini, sebagaimana kesan dalam novelnya, dikemas dengan nada yang amat kocak, sekalipun tetap mendidik. Meski dengan penuturan yang berbeda dari novel aslinya, ditambah totalitas para pemain yang sebagian besar adalah asli bocah Belitong, semangat dan nilai-nilai yang diusung dalam film ini telah mengena, hingga membasahimeminjam istilah Syafi'i Ma'arif-titik nadir kesadaran manusia, berbanding lurus dengan prinsip-prinsip nilai yang diusung oleh novelnya. 


\section{DAFTAR PUSTAKA}

Ali, Hamdani, H.B., 1993, Filsafat Pendidikan, (Yogyakarta: Penerbit Kota Kembang), cet.3

Dewey, John, 1966, A Pragmatic Method, dalam Jack Pustilnick and Dale Riepe (ed.), "The Structure of Philosophy" (New Jersey: Littlefield, Adam \& Co), hlm 199-204

2004, Experience $\mathcal{E}$ Education, terj. dari Bahasa Inggris oleh Hani'ah (Jakarta: Penerbit Teraju), cet.1

Freire, Paulo dkk. (ed.), 2006, Menggugat Pendidikan: Fundamentalis, Konservatif, Liberal, Anarkis, terj. dari bahasa Inggris oleh Omi Intan Naomi, (Yogyakarta: Pustaka Pelajar), cet. 6

Gutek, Gerald L., 1988, Philosophical and Ideological Perspectives on Education, (New Jersey: Prentice-Hall Inc.)

Hirata, Andrea, 2007, Laskar Pelangi (Novel), (Yogyakarta: Bentang Pustaka), cet. 14 2008, Maryamah Karpov (Novel), (Yogyakarta: Bentang Pustaka), cet. 2

Knight, George R., 2007, Filsafat Pendidikan, terj. dari bahasa Inggris oleh Mahmud Arif, "Issues and Alternatives in Educational Philosophy", (Yogyakarta: Gama Media kerjasama CDIE (Center for Developing Islamic Education) Fakultas Tarbiyah UIN Sunan Kalijaga), cet. 1

Reza, Riri (Sutradara) \& Mira Lesmana (Produser), 2008, Laskar Pelangi (Film), ditonton pada Kamis, 25 September 2008 jam 13.00-15.00 WIB dan Senin, 10 November 2008, jam 16.00-18.00 WIB

Rowlands, Mark, 2004, Menikmati Filsafat Melalui Film Science-Fiction, terj. dari bahasa Inggris oleh Sofia Mansoor, "The Philosopher at the End of the Universe: Philosophy Explained Through Science Fiction Films", (Bandung: Penebit Mizan), cet. 1

O'Neill, William F., 2002, Ideologi-Ideologi Pendidikan, terj. dari bahasa Inggris oleh Omi Intan Naomi, "Educational Ideologies: Contemporary Expressions of Educational Philosophies", (Yogyakarta: Pustaka Pelajar), cet. 2 
212 Jurnal Filsafat, Vol. 27 No. 2 Agustus 2017

Sudarminta, 2004, Pengalaman sebagai Basis Pendidikan, kata pengantar buku "Experience \& Education", terj. dari Bahasa Inggris oleh Hani'ah (Jakarta: Penerbit Teraju), cet.1, hlm. vii-xv

Zuriah, Nurul, 2007, Pendidikan Moral E Budi Pekerti dalam Perspektif Perubahan: Menggagas Platform Pendidikan Budi Pekerti Secara Kontekstual dan Futuristik, (Jakarta: PT Bumi Aksara), cet.1 